\title{
Risk Management in the Healthcare Sector and the Important Role of Education and Training Activities: The Case of Regione Lombardia
}

\author{
Alessandro Capocchi ${ }^{1}$, Paola Orlandini ${ }^{1}$, Mariarita Pierotti ${ }^{1}$, Loredana Luzzi ${ }^{1} \&$ Lorenzo Minetti ${ }^{1}$ \\ ${ }^{1}$ Department of Business Economics and Law, University of Milano Bicocca, Italy \\ Correspondence: Alessandro Capocchi, Department of Business Economics and Law, University of Milano \\ Bicocca, Italy. E-mail: alessandro.capocchi@unimib.it
}

Received: September 5, 2018

Accepted: November 24, 2018

Online Published: December 30, 2018

doi:10.5539/ijbm.v14n1p180

URL: https://doi.org/10.5539/ijbm.v14n1p180

\begin{abstract}
Purpose-Risk is intrinsically linked to all economic activity, and can never be completely eliminated; however, in certain cases and conditions, it can be mitigated. From the managerial perspective, it is possible to distinguish between speculative risks and pure risks. This distinction is made in relation to the effects produced from particular events on the economic conditions of the company. Speculative risks can lead to profits or losses, as they are connected to both unfavorable and favorable events, whereas pure risks uniquely produce losses or negative effects. There have been several studies on this topic from various perspectives. Our paper is based on an empirical investigation that aims to verify whether there is a direct or indirect correlation between risk-management policies in the healthcare sector and education and training activities.

Design/methodology/approach-The analysis is based on an inductive research method that uses the case study methodology in order to verify and measure the direct or indirect correlation between risk-management policies and education and training activities in the healthcare sector of Regione Lombardia.

Findings - The paper makes a clear contribution to the knowledge related to risk-management policies in the healthcare sector. Based on the case study of Regione Lombardia, integrates the dimensions of organization and individuals with the cross-section of education and training in new risk-management systems.

Research limitations/implications - This paper has several limitations. First, it considers only a single case, in Regione Lombardia. The distinctive features of the case may have led to specific empirical evidence and, moreover, the empirical evidence cannot be generalized to other territorial contexts/destinations. Second, the data set is limited to five years and is not sufficient to measure the direct correlation between the two aspects under study.

Originality/value-This is the first paper to have approached, using an inductive research method, the issue of risk management connected to the education/training dimension by analyzing the case of Regione Lombardia. The findings should stimulate new debate in the business economics literature.
\end{abstract}

Keywords: risk management, healthcare, education, training, Lombardia, performances

\section{Introduction}

The issue of risk management (RM) within the Italian National Healthcare System has assumed increasing importance in the last 10 years due to the increasing incidence of malpractice and consequent litigation. The economic scenario and the need to optimize investment into public resources have led the governments of the different countries (not only in Italy) to use specific measures to increase the efficiency of the National Healthcare System. In particular, the Italian National Health Service (SSN) sought to contain spending on infrastructural and technological investments in the period 2003-2010 (the percentage of fixed capital investments in the healthcare field was equal to $2.6 \%$ of total expenditure. More recently, new laws aimed at improving healthcare accounting systems have imposed limits on the use of the resources coming from the current management to realize new investments (Longo and Cantù, 2013). The mechanisms introduced with these laws involve penalizing the more virtuous healthcare organizations, limiting the realization of innovation policies. Moreover, the Italian epidemiologic context is now dominated by the prevalence of geriatric pathologies and chronic-degenerative conditions that require ongoing and specific healthcare assistance (including home care), which leads to a progressive increase in spending. As Armeni et al. (2016) observed, the 
progressive ageing of the population, changes in the average lifestyle, and the negative environmental impact on general health are influencing the demand for assistance, which is becoming more and more complex. For these reasons (among others), clinical governance policies are becoming especially important in terms of contributing to realizing a sustainable national healthcare system oriented toward the real dynamics and needs of the population (Arduini \& Luzzi, 2016).

As Fusco et al. (2017: 33) stated, "The objective is (...) to guarantee a more efficient and effective management of the organizations and the healthcare systems in terms of better security and quality of treatments, as well as of rationalization of the company costs." In this new framework, RM is becoming very important. The risk-identification, -assessment, and -management processes are part of companies' strategic development; they must be designed and planned at the highest level, and an integrated risk-management approach must evaluate, control, and monitor all risks and their dependences to which the company is exposed.

In general, a pure risk is a combination of the probability or frequency of an event and its consequences, which are usually negative. The probability of an uncertain event occurring is often unknown, as are its consequences. In this case, it is more important to apply precautionary than preventive measures to protect against uncertainty. Our research, in line with Lucas' (1997) and Reason's (2001) approach, aims to contribute to the literature analyzing the relationship between RM and the role of education and training activities in health management. We use the case study research method, as a continuation of the recent contribution by Fusco et al. (2017). Our study provides a brief overview of the model used in healthcare in Regione Lombardia and analyzes empirical data collected from Polis Lombardia (Regional institute for the support of Lombardy policies) in order to verify whether there is a concrete (direct or indirect) correlation between education and training activities and RM in the regional healthcare system. In particular, our research, following Fusco et al. (2017), aims to underline how education and training in health management become part of the risk-management system in order to reduce clinical and nonclinical claims, and to improve the efficiency of both technical and economic aspects of the entire regional system.

\section{Literature Review}

RM in healthcare can be defined as a system composed of several processes by which organizations try to estimate, measure, and prevent risk in order to reduce negative impacts on different variables, such as technical and economic aspects.

During recent decades, there has been a transition from insurance coverage as the only or the main solution to $\mathrm{RM}$, to the adoption and implementation of managerial tools, techniques, and methodologies in order to anticipate business risk (Messano et al., 2014). RM has long been associated with the use of market insurance to protect individuals and companies from various losses associated with accidents (Harrington and Niehaus, 2003). New forms of pure RM emerged as alternatives to market insurance when different types of insurance coverage became very expensive, less accessible, and incomplete. Without analyzing the history of RM, it is important to observe how RM is currently considered at a corporate level — even in the healthcare system - in order to create a reference framework that will allow companies to handle risk and uncertainty (Vincent, 2006). Adversity in the healthcare system may be defined as unintended injury or complication resulting in disability, death, or prolonged hospital stay that is caused by healthcare management, rather than by the patient's underlying disease process (Cagliano et al., 2011; Ross Baker et al., 2004).

In the healthcare systems, Cagliano (2011) observed that the probability of errors and adverse events cannot be eliminated, but can be controlled through the implementation of a recursive process of continuous improvement inspired by the Plan, Do, Check, Act (PDCA) paradigm (Tonneau, 1997).

Various kinds of risks have been considered in the literature; following Cagliano (2011), we focus on clinical risks, which can be defined as clinical error due to a deviance from intended treatment, care, therapeutic intervention, or diagnostic result (Sale, 2005). In particular Kohn, Corrigan, and Donaldson (1999) defined clinical risk as the probability that a patient is affected by an adverse event caused by voluntary or involuntary medical treatments. However, clinical risk not only arises in relation to medical activities that directly affect patients - it is reliant on a larger set of activities and professionals. Risk can be determined by many factors related to the system, the environment, and the interplay of individuals operating in the processes connected to the delivery of care (Kohn et al., 1999). This point is important to justify the corporate approach to RM (Vincent, 2001), as more than $50 \%$ of adverse events in healthcare systems can be prevented, as demonstrated in studies performed in Australia, Europe, New Zealand, and US (Davis et al., 2001; Leape et al., 1991; Vincent et al., 2001; Wilson et al., 1995). This highlights a strong need to understand the events that trigger medical errors, as well as their correlations, in order to decrease the probability that such errors will occur. 
According to Reason (2002), adverse events are seldom determined by a single error, whether human or technological; more often, they are the result of a chain of errors and events in which the person responsible for the final error is only the last causal link (Reason, 2002). Reason's model defines an adverse event as an unexpected release of energy that may be prevented by erecting barriers between the source of the energy and the person or object to be protected (Harms-Ringdahl, 2009).

Lucas (1997) followed by Reason (2001) and by other authors (Harms-Ringdahl, 2009; Henriksen et al., 2008; Paz Barroso and Wilson, 2000; Wiegmann and Shappell, 2001) have suggested that in order to reduce the incidence of errors in the healthcare system it is necessary to develop a model of RM mainly based on four integrated dimensions: organizational (systemic), individual, technical, and psychological. Following this approach, our research aims to underline how education and training can be considered a cross-sectional dimension between the organization and the individual. If it is true - as Lucas (1997) and Reason (2001) demonstrated - that people's behavior is highly influenced by the organizational system in terms of working environment and operational processes, the role of education and training in health management can be a valid source of support to increase the barriers to adverse events (Cosby, 2003). At the same time, education and training are important in the individual dimension in terms of supporting doctors, paramedics, and managers regarding motivation, interpersonal relationships, learning by doing, and the use of a common "managerial language" made of procedures, roles, and tools (McDonald and Mayer, 2008). No study to date has focused on the role of education and training in healthcare management in order to prevent adverse events and reduce clinical and nonclinical claims.

\section{Method}

Following Fusco et al. (2017), our research aims to verify, via an inductive approach based on the case study of Regione Lombardia, whether, and in which way, the implementation of an education and training system focused on health managerial topics can reduce the clinical risks related to adverse events. In this direction, the case study research method has been adopted for the following reasons: (i) As Eisenhardt (1989) observed, case study is a research strategy that focuses on understanding the dynamics present within single settings, and typically combines data sources such as archives, interviews, questionnaires, and observations. ii) From the same perspective, Yin $(1994,2005)$ stated that case study enables the observation of several variables related to the same phenomenon. This is particularly true in the social sciences. (iii) Yin (1994) also observed that case study enables deep comprehension of a complex phenomenon in practice, through the use of multiple direct sources such as internal documents, surveys, interviews, and direct observations. (iv) The need to directly observe phenomena has made the use of purely statistical quantitative methods not always adequate; with the case study method, the researcher can reduce possible measurement errors (Gobo, 2004). (v) Finally, the case study research method is a very good way to start the empirical analysis of new or specific phenomena that can activate new debates in the literature and drive future creation of quantitative models. This is particularly true for the social sciences, where "building theory from case study research is most appropriate in the early stages of research on a topic or to provide freshness in perspective to an already researched topic" (Eisenhardt, 1989: 548).

\section{The Case of Regione Lombardia}

\subsection{Clinical Risk in Regione Lombardia}

In Regione Lombardia, in the observed period 1999-2016, almost 38,000 claims for damages were made to/from the damaged party (judicial and extra-judicial actions) for damages sustained in clinical or assistance activities: $86 \%$ were generated in the ASST (territorial health care organization), $8 \%$ in Foundations, and $6 \%$ in and ATS (organization for the protection of health). (AON, 2016)

The trend of claims for damages peaked in 2009, with 2,340 claims, while in 2016 a decrease in the number of claims for damages of $-5.5 \%$ was recorded compared to the same data in 2015 respectively 1,841 and 1,949 (AON, 2016).

In the 18 years observed, several events led to claims for damages in civil proceedings. These related to first aid or ER (15.3\% of cases), orthopedics and traumatology (14.2\%), general surgery $(9.7 \%)$, obstetrics and gynecology $(9.0 \%)$, general medicine (3.8\%), ophthalmology (3.6\%), neurosurgery $(2.9 \%)$, and otorhinolaryngology and audiology (2.7\%). Another $11.2 \%$ of cases were identified as not directly related to a specialty or service. These were events (such as falls or damage) that occurred in stairways, entrances, parking lots, or driveways.

In 2016 the number of complaints related to orthopedics and traumatology, obstetrics and gynecology, and first aid decreased compared to 2015. Over the 18 years analyzed, hospital specialties (specialties or health support 
services) that generated the most claims for damages in civil proceedings were orthopedics and traumatology $(15.2 \%$ of cases), first aid $(12.2 \%)$, general surgery $(9.3 \%)$, obstetrics and gynecology $(8.8 \%)$, general medicine (3.7\%), ophthalmology $(3.6 \%)$, radiology $(3.1 \%)$, neurosurgery $(2.9 \%)$, otorhinolaryngology, and audiology $(2.5 \%)$. Another $11.2 \%$ of cases were identified as "structure"-i.e., referring to events not directly related to hospital specialties.

The most frequent events in first aid were diagnostic errors $(60.2 \%)$, followed by medication errors $(12.5 \%)$, surgical errors $(5.0 \%)$, and losses $(4.2 \%)$. The most frequent cases in orthopedics and traumatology concerned surgical errors $(54.2 \%)$, followed by diagnostic errors $(10.9 \%)$, therapeutic errors $(9.0 \%)$, and infections $(8.5 \%)$. The most frequent cases in general surgery concerned surgical errors $(50.5 \%)$, diagnostic errors $(10.5 \%)$, infections (7.5\%), and anesthetic errors (6.2\%). In obstetrics and gynecology, the most frequent events concerned surgical errors $(40.0 \%)$, diagnostic errors $(20.1 \%)$, and therapeutic errors $(10.9 \%)$. In general medicine, losses represented $21.2 \%$ of complaints and falls $17.1 \%$, followed by diagnostic errors $(15.5 \%)$ and therapeutic errors $(9.7 \%)$.

The most frequent events during emergency/urgent services (representing $16.99 \%$ of the total events) concerned diagnostic errors in the emergency department (at 39.53\%). Of the damage claims submitted to the ATS, $18 \%$ concerned events not directly attributable to the activity of the ATS itself (damage to property or falls within the area covered by the ATS); $4 \%$ of requests pertained to diagnostic errors in the territorial assistance service, $3 \%$ to infections arising from poor hygiene in the service of food of animal origin, and $2 \%$ to damage to things in the context of the disabled service (AON, 2016).

\subsection{The economic Impact of Clinical and Nonclinical Damages and Claims}

An important point is based on the economic impact of clinical and nonclinical claims in the regional healthcare system. Claims for damages that in the 18 years of analysis have seen a definition (equal to $41 \%$ of total requests) were worth over $€ 871$ million, of which $97.7 \%$ were derived from events generated by hospital activities and $1.0 \%$ from those in the local health sector.

The average amount paid exceeded $€ 56,000$ for claims for damage related to hospital activities, varying from an average of $€ 475$ for thefts to almost $€ 170,000$ for self-harm; the average amount of liquidation related to territorial activity was over $€ 22,000$, varying from $€ 331$ for theft to almost $€ 338,000$ due to therapeutic errors.

The highest percentage of the amounts paid out by the ASST related to surgical errors $(32.8 \%$ of the amounts cleared), followed by diagnostic (28.9\%) and therapeutic errors (10.8\%).

For ATS, therapeutic errors accounted for $60.4 \%$ of the amounts paid. This was followed by diagnostic errors at $14.8 \%$, infections at $7.9 \%$, service level at $4 \%$, and falls at $3.9 \%$.

Insurance premiums collected net of deductibles in the 18 years of analysis amounted to over $€ 1$ billion, of which almost $€ 882$ million concerned ASST, over $€ 73$ million pertained to ATS, and over $€ 133$ million related to Fondazioni.

In some cases there were also criminal implications related to clinical and nonclinical claims. The distribution of criminal proceedings against organizations of the Regione Lombardia Healthcare System SSR reported on the policies of RCT/O (claims for damages from / on behalf of the injured party) showed the greatest concentration on hospital activities. Overall, deaths accounted for $54.6 \%$ of reported cases. In addition, $18.6 \%$ of the criminal proceedings originated from events that occurred in first aid, while $14.3 \%$ were in obstetrics and gynecology and $8.8 \%$ were in general surgery. Furthermore, $23.2 \%$ of the criminal proceedings originated from diagnostic errors, and $19.0 \%$ from surgical errors.

Finally, for $51 \%$ of the conciliatory mediations there was no accession by the third party; of these, $33 \%$ were for nonparticipation by the insurance company. Where mediation was conducted instead, the success rate was equal to $16 \%$ of cases.

\subsection{Risk Map}

The above figures enable us to create a map of the clinical and nonclinical risks for the regional healthcare system of Regione Lombardia. The risk map is obtained by bringing together the different sources of adversity, as shown in Table 1. 
Table 1. The map of clinical and nonclinical risk

\begin{tabular}{|c|l|}
\hline \multicolumn{2}{|c|}{ Claims and Source of Adversity Event } \\
\hline Risk 1 & Civil liability towards third parties and contractors \\
\hline \multirow{2}{*}{ Risk 2} & Patient Falls \\
\cline { 2 - 2 } & Visitor Falls \\
\hline \multirow{3}{*}{ Risk 3 } & Accidents due to biological risk \\
\cline { 2 - 2 } & Chemical risk accidents \\
\cline { 2 - 2 } & Handling accidents \\
\hline & Injuries from other risks \\
\hline
\end{tabular}

The information in Table 1 allows us to identify different typologies of risk affecting the regional healthcare system and involving several potential sources of adverse events:

$>\quad$ Patient falls - In particular, there was an increase in reports of falls over the years, from 7,559 reports in 2005 to 12,948 in 2016 , equating to an increase of $71.3 \%$. The majority of patients reporting falls were from ASST (86\%), followed by Foundations (8\%) and ATS (6\%).

$>$ Visitor falls-There was a decrease in the number of visitor falls in 2015 compared to the previous two-year period. Most fall reports came from ASST (92\%), followed by ATS and Foundations (both 4\%).

$>$ Biological risk-Biological injuries showed a decreasing trend from 2008. The operative block represents the area in which most of the accident reports occurred for biological risk, followed by general medicine. Most injuries involved nursing staff, followed by the medical management.

$>$ Chemical risk-Accidents related to chemical risk showed a fluctuating trend, with a decrease in 2016 compared to 2015. The peak was recorded in 2005. First aid was the specialty for which the most reports of accidents pertaining to chemical risk related. The most frequently involved professional qualification was nursing staff, followed by technical health personnel-OTA/OSS (nursing staff and health care personnel).

$>$ Handling risk-Handling accidents showed a decreasing trend after 2009 (peak year). General medicine was the specialty in which the most reports of handling accidents occurred, followed by general medicine, orthopedics, and traumatology, respectively. The most frequently involved professional qualification was nursing staff, followed by technical health personnel-OTA/OSS.

$>\quad$ Other risks - Accidents from other risks showed a slight decrease in 2016 compared to 2015. The peak was recorded in 2010. The majority of accidents occurred "in itinere," followed by injuries related to "structure" (common areas). The most frequently involved professional qualification was nursing staff, followed by technical health personnel-OTA/OSS.

In order to create a managerial system that is capable of managing the several kinds of clinical and nonclinical risks in the regional healthcare system, in 2004 Regione Lombardia created and activated a roadmap for monitoring $\mathrm{RCT} / \mathrm{O}$ ( $\mathrm{RCT} / \mathrm{O}$ is the civil liability towards third parties and contractors) risks mainly based on: a unique regional database; a regional and business reporting system; a benchmarking report able to normalize the various parameters; an informative system in order to share the process with related companies; and SIMES (national monitoring system) power supply (since 2009). At the same time, a Claims Assessment Committee was activated.

The system created by Regione Lombardia is a multidimensional model in which a central role is played by RM activity, but where the relationships with insurance companies and between patient and doctor also have a significant role. In 2015, Regione Lombardia issued at regional level the first guidelines for RM activities.

Until 2011, each organization of the SSR autonomously defined the extent of insurance coverage. In 2011, an analysis project was launched by DG Health to evaluate the opportunity to centralize strategies and/or RM/mitigation processes; between December 2012 and December 2014, four separate "centralized" tender procedures were carried out involving almost all the structures involved in the project: 29 AO (hospitals), 1 ASL (healthcare organization), 4 IRCCS (Scientific Institutes of Hospitalization and Care).

\subsection{Education and Training Activities}

An academy for the social and healthcare service of Regione Lombardia was established based on art. 17 bis "Training system for the Lombard socio-economic system" of the Law 33/03/2009 "Consolidated text of regional health laws." The mission of the academy is to support the Regional Council in the design and provision of education and training activities for all members of the regional healthcare system in order to guarantee and 
promote the provision of excellent services and the correct balance between the needs of human resources with distinctive skills and the regional training supply system. The academy (i) promotes and guarantees the excellence of the Lombardy Health System (SSL), also integrating services with the teaching, assistance, and research functions of the SSL; (ii) coordinates the training network in agreement with the Integrated Observatory of the SSL; (iii) guarantees the compulsory nonuniversity specialist training required by national legislation; (iv) provides in the SSL the training network and the promotion and implementation of multidisciplinary training paths, transversal to the levels of classification and specializations, and takes care of the training needs necessary for implementation of the SSL in line with provisions of the Integrated Social Health Plan of Regione Lombardia (PSL); (v) promotes horizontal subsidiarity between the training network and agencies and the free choice of professionals in accessing continuing education; (vi) verifies the training obtained abroad by staff of the Sanitary System of Lombardy, promotes the internationalization of training courses in order to pursue innovation for professionals of the SSL and attract excellent personnel from abroad, in collaboration with the agency that promotes the SSL; (vii) promotes courses in strategic training on health policies and continuous innovation of the SSL (healthcare national system), in assistance, research and teaching, having heard the integrated Observatory of the SSL; and (viii) ensures transparency of SSL's investments into human capital, reporting annually and on a three-year basis the budget of the AFSSL training activity. During the last five years, just concerning risk-management subjects, the academy provided courses lasting several hours and to several participants, as represented in Table 2.

Table 2. Academy's risk-management courses in the last six years (2012-2016)

\begin{tabular}{|c|c|c|}
\hline Year & Participants & Classroon Hours \\
\hline 2012 & 544 & 110 \\
\hline 2013 & 393 & 101 \\
\hline 2014 & 418 & 106 \\
\hline 2015 & 274 & 74 \\
\hline 2016 & 532 & 71 \\
\hline
\end{tabular}

Table 2 shows that between 2012 and 2016, the academy provided risk-management training and other education activities, reducing the numbers of hours in the classroom and increasing the number of participants..

\section{Findings and Discussion}

In the 18 years analyzed, $42.1 \%$ of the total compensation of claims has been defined, for a value of over $€ 871$ million, of which $97.7 \%$ derived from events generated by hospital activities and $1.0 \%$ pertained to the local health sector. Globally, in the period considered the average amount paid equaled over $€ 56,000$.

The average amount paid was over $€ 75,000$ in relation to clinical risk, over $€ 1,400$ for accidental damage, $€ 10,000$ for worker's risk, and almost $€ 22,000$ for structure risk.

The distribution of damage claims is represented in Figure 1. 


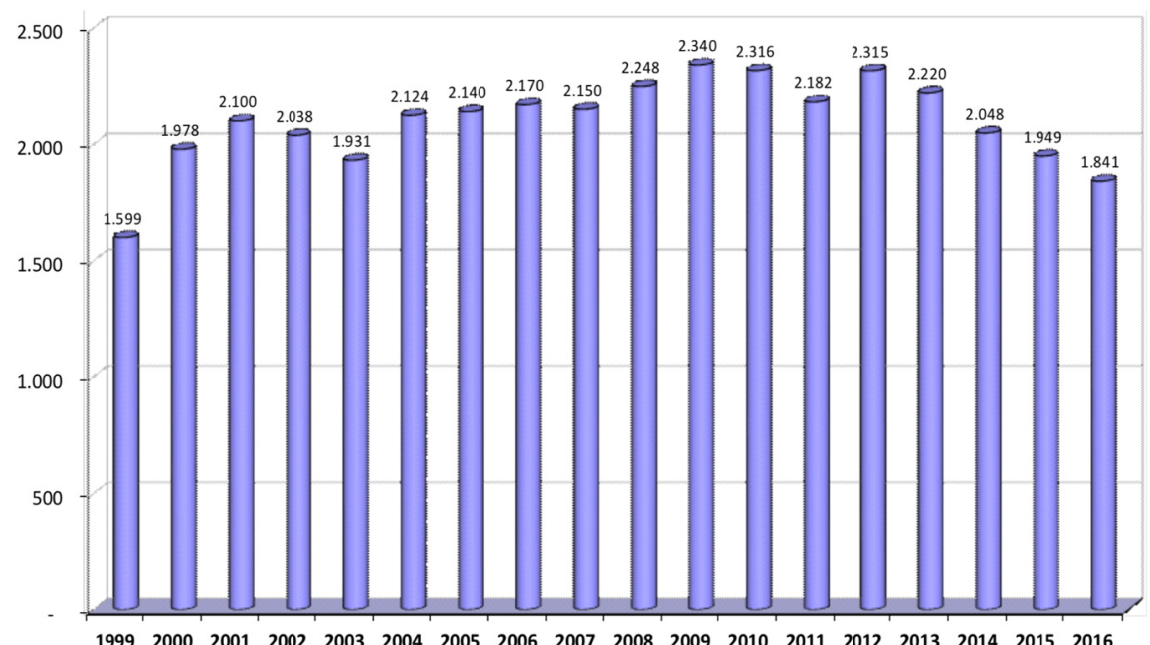

Figure 1. Distribution of damage claims for 1999-2016

In particular, in order to measure the correlation with training and educational activities provided by the academy, the number of damage claims over the last five years is indicated in Table 3.

Table 3. Numbers of damage claims in the period 2012-2016

\begin{tabular}{|c|c|c|c|}
\hline Year & Damage Claims & $\begin{array}{c}\text { Change on } \\
\text { annaul basis }\end{array}$ & $\begin{array}{c}\text { Progressive } \\
\text { Change }\end{array}$ \\
\hline 2012 & 2316 & $-0,04$ & $-0,04$ \\
\hline 2013 & 2223 & $-0,08$ & $-0,12$ \\
\hline 2014 & 2048 & $-0,05$ & $-0,17$ \\
\hline 2015 & 1949 & $-0,06$ & $-0,22$ \\
\hline 2016 & 1841 & $-1,00$ & $-1,22$ \\
\hline
\end{tabular}

Observing the trend regarding the number of claims for damages shown in Table 3, there was a significant change starting in 2012; this was the same year in which Regione Lombardia started to use a systemic approach to health management through the academy.

Figure 2 shows an increasing trend in the number of damage claims for the period 1999-2012, where the average growth of requests in the same period was $€ 55.31$ million. On the contrary, from 2.012-2016 there was a decreasing trend, with an average decrease equal to $€ 118.75$ million.

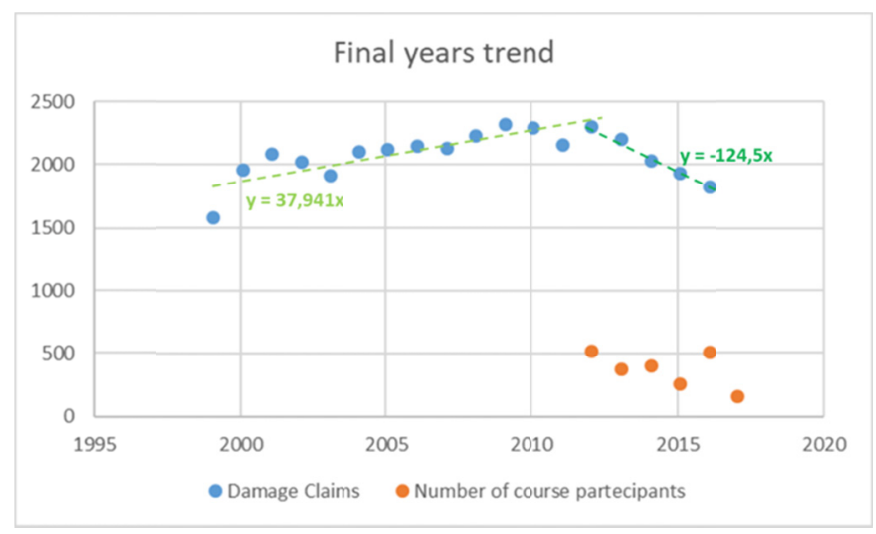

Figure 2. Damage claims, 1999-2012 
To measure the implications of the education and training activities, Table 4 shows, for each year, the total number of participants, classroom hours, and course value (calculated by multiplying the number of participants with the number of hours). Finally, the last column indicates the number of claims for damages.

Table 4. Significant education/training activities data

\begin{tabular}{|ccccc|}
\hline Year & Partecipants & Hours & $\begin{array}{c}\text { Value of the } \\
\text { course (X) }\end{array}$ & $\begin{array}{c}\text { Damage } \\
\text { claims (Y) }\end{array}$ \\
2012 & 544 & 110 & 59840 & 2316 \\
2013 & 393 & 101 & 39693 & 2223 \\
2014 & 418 & 106 & 44308 & 2048 \\
2015 & 274 & 74 & 20276 & 1949 \\
2016 & 532 & 71 & 37772 & 1841 \\
2017 & 179 & 71 & 12709 & - \\
\hline
\end{tabular}

Using the matrix in Table 4, it is possible to measure the direct correlation coefficient between the value of the courses $(\mathrm{X})$ and the number of claims for damages $(\mathrm{Y})$, using the following formula:

$$
\rho(X, Y)=\frac{\sigma(X, Y)}{\sigma(X) \sigma(Y)}=0,69
$$

The value obtained from the above formula indicates a positive direct correlation between the decrease in compensation claims and the decrease in the value of the courses. However, this finding must be read with caution, as the figure could be interpreted in a counterintuitive and contrary way that is not faithful to reality. For instance, it could be erroneously argued that a reduction in education and training activities had a positive impact on the decreasing trend regarding the number of claims. However, this cannot be true for three main reasons: (i) education for doctors, paramedics, and managers is not the main asset and has no direct impact on the number of claims for damages; (ii) the period considered for the observation regarding education and training activities is not large enough to measure a direct correlation between these activities and the impact on the number of claims; and (iii) the impact of education and training activities in terms of outcome on the number of damage claims can only be measured over the medium and long term.

To analyze the full 18 years, instead of using the course value we use a dummy variable that takes a value of 1 in the year where the course was implemented and 0 otherwise. Thus, we can include all years without the course value. The idea is to allow the regression to create two groups of years: one with courses (2012-2016) and another without (1999-2011). We can then see the differences between years with courses and years without courses in terms of the number of claims according to the model in Table 5. 
Table 5. Dummy variable analysis

\begin{tabular}{cllll} 
Claims $_{\boldsymbol{t}}=$ Dumm_c $_{\boldsymbol{c}} \boldsymbol{c o u r s} \boldsymbol{e}_{\boldsymbol{t}}$ & & & \\
\cline { 2 - 5 } Year & Number of claims & Course? & Dummy \\
\hline 1999 & 1599 & No & 0 \\
2000 & 1978 & No & 0 \\
2001 & 2100 & No & 0 \\
2002 & 2038 & No & 0 \\
2003 & 1931 & No & 0 \\
2004 & 2124 & No & 0 \\
2005 & 2140 & No & 0 \\
2006 & 2170 & No & 0 \\
2007 & 2150 & No & 0 \\
2008 & 2248 & No & 0 \\
2009 & 2340 & No & 0 \\
2010 & 2316 & No & 0 \\
2011 & 2182 & No & 0 \\
2012 & 2315 & Yes & 1 \\
2013 & 2220 & Yes & 1 \\
2014 & 2048 & Yes & 1 \\
2015 & 1949 & Yes & 1 \\
2016 & 1841 & Yes & 1 \\
\hline
\end{tabular}

The results are presented in Table 6 . They clearly show that, in terms of claims, there was no difference between years with courses and years without. However, the analysis is limited due to the small number of years with courses. This could be improved by adding more years with courses, along with other control variables.

Table 6. Dummy variables analysis evidences

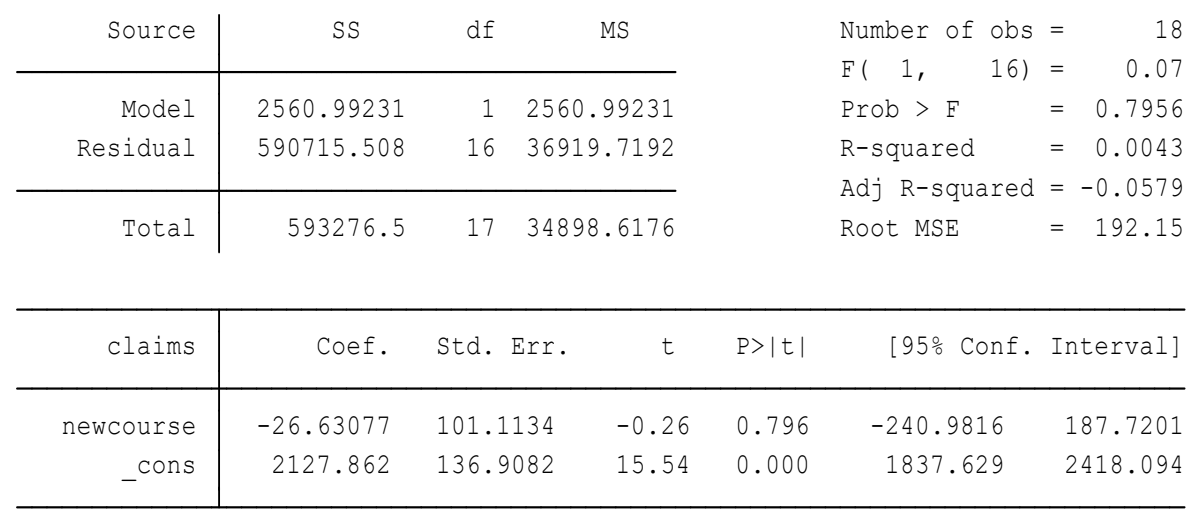

\section{Conclusions and Future Research Directions}

Our investigation follows Lucas' (1997) and Reason's (2001) approach in analyzing the relationship between $\mathrm{RM}$ and education and training activities in risk management, using the case study research method as a continuation of a recent contribution by Fusco (Fusco et al., 2017), and considering the case of Regione Lombardia.

RM is becoming very important, as litigation claims are increasing to such an extent that no hospital or health authority budget is safe from what can prove to be financially crippling payments of damages and costs (O’Donovan, 1997). Doctors and paramedic staff need to be aware of the hazards that can affect patient safety. According to O'Donovan (1997), RM is an integrated system in which an organization adopts a proactive approach to the management of future uncertainty, allowing for identification of methods for handling risks that may endanger people, property, financial resources, and credibility, and involving the systematic analysis of actual and potential risks, and the development and implementation of measures to reduce or eliminate these. 
RM activities are designed specifically to identify actual or potential hazards related to patients' and staff safety, and to effectively reduce these hazards so that patient care is improved and cases of negligence are reduced.

The main focus of our research was on demonstrating the direct and/or indirect correlation between education and training activities and the decreasing number of claims for damages.

Education and training are one of the main factors that, together with the organization, psychology, professionalism, and technology, contribute to determining the clinical risk. Only by determining and deepening the individual factors it is possible to ensure that risk is effectively controlled.

The findings of our investigation demonstrate that there is a slight direct correlation between education and training activities and the trend in the number of claims for damages during the observed period. The correlation is not so strong because the dataset is limited and the observed period is not extensive; the outcome from education and training activities must be measured over the medium and long term. What it is clear is the indirect correlation between education and training activities and the trend regarding the number of claims for damages. The indirect correlation is demonstrated by the role of the organization and individual in the integrated RM system. In this direction, according to the prevailing literature, education and training represent a cross-sectional dimension that has increasing importance in terms of their impact on individual and team motivation, responsibility and accountability, optimization of the processes, and implementation of a unique "managerial language," which is at the base of any modern RM system. In the future, observing an extended period and segmenting the data will provide more accurate measurements and help to support a direct correlation.

\section{References}

Arduini, R., \& Luzzi, L. (2017). Economia e gestione delle aziende sanitarie. Franco Angeli.

Baker, G. R., Norton, P. G., Flintoft, V., Blais, R., Brown, A., Cox, J., \& O'beirne, M. (2004). The Canadian Adverse Events Study: the incidence of adverse events among hospital patients in Canada. Canadian Medical Association Journal, 170(11), 1678-1686. https://doi.org/10.1503/cmaj.1040498

Barresi, G. (2013). Il rischio clinico nelle aziende ospedaliere: strumenti di analisi e profili di gestione. FrancoAngeli.

Bertini, U. (1987). Introduzione allo Studio dei Rischi in Economia Aziendale, Cursi. (LA PRIMA EDIZIONE E' PERò DEL 1969)

Cagliano, A. C., Grimaldi, S., \& Rafele, C. (2011). A systemic methodology for risk management in healthcare sector. Safety Science, 49(5), 695-708. https://doi.org/10.1016/j.ssci.2011.01.006

Cantù, E., \& Longo, F. (2013). Rapporto OASI 2013. L'aziendalizzazione della sanità italiana, CERGAS-EGEA.

Cosby, K. S. (2003). A framework for classifying factors that contribute to error in the emergency department. Annals of emergency medicine, 42(6), 815-823. https://doi.org/10.1016/S0196-0644(03)00635-8

Costa, F., Armeni, P., Otto, M. H., Amoroso, N., \& Jommi, C. (2016). La rendicontazione e la remunerazione dei farmaci. Finalità, struttura e gestione del File F in nove Regioni italiane. Mecosan.

Dezzani, F. (1971). Rischi e politiche d'impresa: contenuto e relazioni. Giuffrè.

Eisenhardt, K. M. (1989). Building theories from case study research. Academy of management review, 14(4), 532-550. https://doi.org/10.5465/amr.1989.4308385

Floreani, A. (2004). Enterprise Risk Management: I rischi aziendali e il processo di risk management. EDUCatt-Ente per il diritto allo studio universitario dell'Università Cattolica.

Fusco, A., Dicuonzo, G., Dell'Atti, V., \& Amoo, N. (2017). The clinical risk management: A case study. Management Control. https://doi.org/10.3280/MACO2017-003003

Gobo, G. (2004). Sampling, representativeness. Qualitative research practice, 435.

Harms-Ringdahl, L. (2009). Analysis of safety functions and barriers in accidents. Safety Science, 47(3), 353-363. https://doi.org/10.1016/j.ssci.2008.06.004

Harrington, S. E., \& Niehaus, G. (2003). Capital, corporate income taxes, and catastrophe insurance. Journal of Financial Intermediation, 12(4), 365-389. https://doi.org/10.1016/j.jfi.2003.07.001

Henriksen, K., Dayton, E., Keyes, M. A., Carayon, P., \& Hughes, R. (2008). Understanding adverse events: a human factors framework. 
Knight, F. H. (1921). Risk, uncertainty and profit. New York: Hart, Schaffner and Marx.

Kohn, L. T., Corrigan, J. M., Donaldson, M. S., \& To, E. (1999). To En-Is Human: Building a Safer Health System. Washington, DC: Institute of Medicine.

Leape, L. L., Brennan, T. A., Laird, N., Lawthers, A. G., Localio, A. R., Barnes, B. A., ... \& Hiatt, H. (1991). The nature of adverse events in hospitalized patients: results of the Harvard Medical Practice Study II. New England Journal of Medicine, 324(6), 377-384. 10.1056/NEJM199102073240605

Lucas, D. (1997). The causes of human error. In: Redmill, F., Rajan, J. (Eds.), Human Factors in Safety-Critical Systems. Reed Educational and Professional Publishing Ltd., Oxford, UK.

Marchi, L. (2014). Nuove prospettive di valutazione delle performance nelle aziende di servizi. Management Control, 1, 5-8.

McDonald, T., \& Mayer, D., (2008). Full Disclosure Is More Than Saying “I’m Sorry”. Focus on Patient Safety 11(1), 1-3.

Messano, G., De Bono, V., Di Folco, F., \& Marsella, L. (2014). Past and present of risk management in healthcare. SANITÀ PUBBLICA, 421-427.

O’Donovan, M. (1997). Risk management and the medical profession. Journal of Management Development, 16(2), 125-133. https://doi.org/10.1108/02621719710164292

Paz Barroso, M., \& Wilson, J. R. (2000). Human Error and Disturbance Occurrence in Manufacturing Systems (HEDOMS): A Framework and a Toolkit for Practical Analysis. Cognition, Technology \& Work 2,51-61

Reason, J., (2001). Understanding adverse events: the human factor. In Vincent, C. (Eds.), Clinical risk management: enhancing patient safety (2nd ed.). BMJ Books, London, UK.

Reason, J. (2002). Combating omission errors through task analysis and good reminders. Quality and Safety in Health Care, 11(1), 40-44. http://dx.doi.org/10.1136/qhc.11.1.40

Reginato, E., Nonnis, C., \& Pavan, A. (2012). Modern public internal control systems and accountability in health care organisations. Economia Aziendale Online, 2(4), 381-396. http://dx.doi.org/10.4485/ea2038-5498.381-396

Regione Lombardia - AON. (2016). Mappatura del rischio del sistema sanitario regionale. Risultati tredicesima edizione.

Sale, D. (2005). Understanding clinical governance and quality assurance: Making it happen. Palgrave Macmillan.

Sassi, S. (1940). Il sistema dei rischi d'impresa. Vallardi.

Tonneau, D. (1997). Management tools and organization as key factors towards quality care: reflections from experience. International Journal for Quality in Health Care, 9(3), 201-205. https://doi.org/10.1093/intqhe/9.3.201

Vincent, C. (2006). Patient safety (p. 42). Edinburgh: Churchill Livingstone.

Vincent, C., Neale, G., \& Woloshynowych, M. (2001). Adverse events in British hospitals: preliminary retrospective record review. Bmj, 322(7285), 517-519. https://doi.org/10.1136/bmj.322.7285.517

Wagner, E. H., Austin, B. T., Davis, C., Hindmarsh, M., Schaefer, J., \& Bonomi, A. (2001). Improving chronic illness care: translating evidence into action. Health affairs, 20(6), 64-78. https://doi.org/10.1377/hlthaff.20.6.64

Wiegmann, D. A., \& Shappell, S. A. (2001). Human error perspectives in aviation. The International Journal of Aviation Psychology, 11(4), 341-357. https://doi.org/10.1207/S15327108IJAP1104_2

Wilson, R. M., Runciman, W. B., Gibberd, R. W., Harrison, B. T., Newby, L., \& Hamilton, J. D. (1995). The quality in Australian health care study. Medical journal of Australia, 163(9), 458-471.

Yin, R. K. (1994). Case study research: Design and Methods, Applied social research methods series, 5. Biography, Sage Publications, London.

Yin, R. K. (Ed.). (2005). Introducing the world of education: A case study reader. Sage. 


\section{Copyrights}

Copyright for this article is retained by the author(s), with first publication rights granted to the journal.

This is an open-access article distributed under the terms and conditions of the Creative Commons Attribution license (http://creativecommons.org/licenses/by/4.0/). 